\title{
DEFORMATION CHARACTERISTICS OF CHOPPED FIBRE COMPOSITES SUBJECTED TO QUASI-STATIC TENSILE LOADING
}

\author{
Jan Šleichrt $^{a, *}$, Marcel Adorna $^{a}$, Michaela Neühauserová $^{a}$, \\ Nela Fenclováa ${ }^{a}$, Veronika Petráñová $^{b}$ \\ ${ }^{a}$ Czech Technical University In Prague, Faculty of Transportation Sciences, Konviktská 20, 12000 Prague 1, \\ Czech Republic \\ ${ }^{b}$ Czech Academy of Sciences, Institute of Theoretical and Applied Mechanics, Prosecká 76, 190 00, Prague 9, \\ Czech Republic \\ * corresponding author: sleicjan@fd.cvut.cz
}

ABSTRACT. This work presents deformation behaviour of cost effective chopped fiber composites. Use of chopped fibre is advantageous for manufacturing however complex shape parts production technology could be challenging. Batches of samples with different fibres composition were subjected to uni-axial tensile loading to obtain overall materials properties and inspection of proper manufacturing based on local deformation inhomogeneities. Both crossbeam displacement and optical strain measurement were used for elastic characteristics evaluation. Deformation response was derived from full-field optical strain measurements based on digital image correlation method. Relatively large variation of mechanical properties testing of samples was found.

KEYWORDS: chopped fibre composites, full-field measurement, digital image correlation.

\section{INTRODUCTION}

Carbon fiber reinforced thermoplastic composite become a standard construction material in last decades mainly for its good strength to weight ratio, chemical resistivity and recyclable [1]. Moreover operating of light weight structures is economically beneficial. Because of damage-tolerance approach used for the composite material a comprehensive knowledge of the material deformation response is required [2]. The high strength composites are in the large majority manufactured as long fibres composited. This material was intensively investigated on macro- mezzo- and micro-level to obtain the detailed information about its deformation response to the various type of the loading [3, 4] and description of the internal damage propagation [5, 6]. However there have excellent mechanical properties its production cost is relatively high and manufacturing of complex shaped parts is challenging. For less loaded complex shaped parts are an appropriate solution usage of chopped fibre composite [7]. This cost effective material allows due to the stochastic orientation of the carbon fibre pellets manufacturing of the parts with variable thickness, holes and branchings [8].

Presented article is focused on deformation behaviour of newly developed chopped fibre composite subjected to quasi-static loading. Prototyped material prepared by custom designed molding system have to be inspected to discover detect defects in materials and to describe its deformation behaviour. Full-field optical strain field measurement method 9] was employed for assessed of reliability of the manufacturing tech-

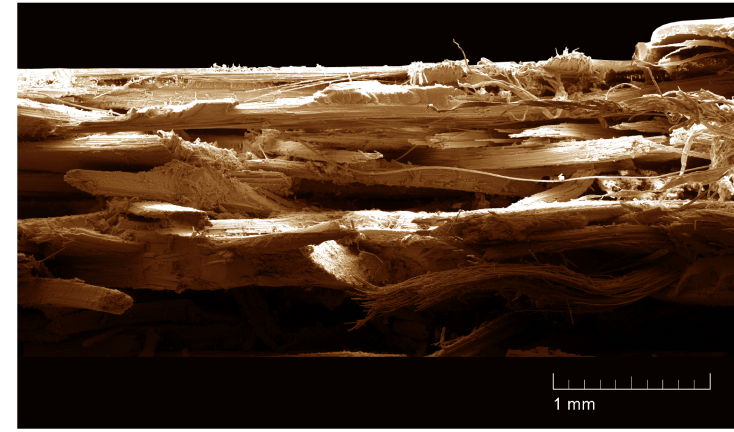

Figure 1. Detail of damage structure after tensile test obtained by scanning electron microscope.

nology based on overall material properties and local deformation inhomogeneities. The collapsed structure of the composite specimen can be seen in Fig. 1

\section{Experimental Procedure}

\subsection{Specimen Description}

Dog bone shaped samples (Fig. 2) with width of $20 \pm 0.4 \mathrm{~mm}$ and thickness of $2.5 \pm 0.1 \mathrm{~mm}$ were manufactured using custom designed mould. Two sets of samples were prepared from carbon pellets with dimensions $25 \times 6 \mathrm{~mm}$ and $13 \times 3.25 \mathrm{~mm}$ respectively bounded with a thermoplastic matrix. Thickness of the pellets was $0.14 \mathrm{~mm}$ in both cases. Density of the final material was around $1.35 \mathrm{~g} \cdot \mathrm{cm}^{-3}$. The orientation of the pellets was completely random because the process of filling pellets into the shape was uncontrolled. The temperature of glass transition was $90^{\circ}$. 


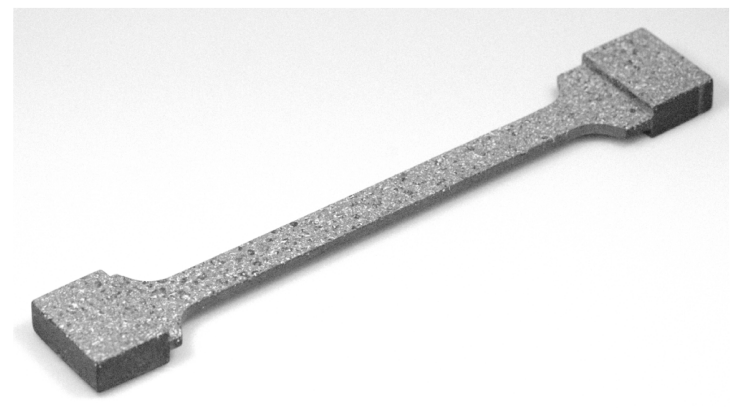

FiguRE 2. Visualization of sample shape.

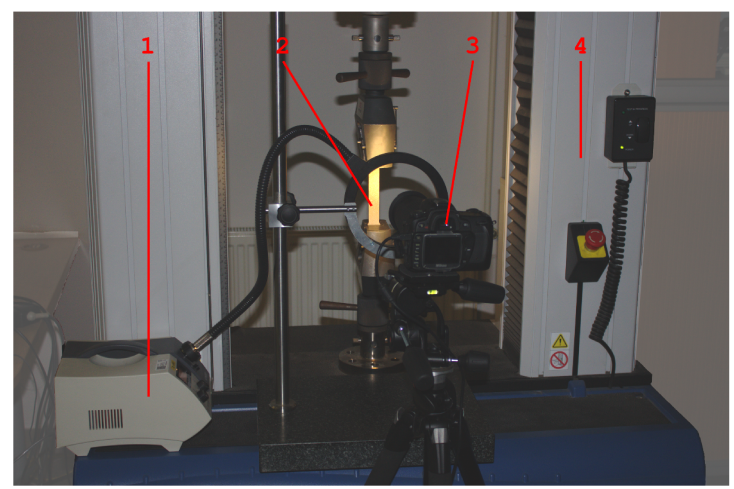

FiguRE 3. Experimental devices: 1-LED light source, 2-specimen, 3-camera, 4-loading device.

Final samples were cut from the plate using water-jet cutter. Finally, the surface of sample was equipped by random pattern point for image processing.

\subsection{Experimental Setup}

Experimental setup consists of Instron 3382 (Instron, Inc.) loading device for tensile measurements and digital single-lens reflex camera with accessories. Displacement controlled tests were performed with $10 \mu \mathrm{m} \cdot \mathrm{s}^{-1}$ loading rate. Force was measured by high-durability load cell with loading capacity $50 \mathrm{kN}$. Strain was measured optically using EOS 550D (Canon, Japan) camera equipped with macro-objective EF100mm/1:2.8L Macro (Canon, Japan). Complete equipment is depicted in Fig. 3 Artificial pattern on the sample surface was illuminated by laboratory LED light source KL 2500 (Shott, Germany). Images were captured in equidistant time intervals and were labeled by unique time stamp for a precise synchronization of DIC and force $\log$.

\subsection{Digital Image Correlation}

Strain was evaluated from the acquired image sequence using custom DIC software [10] based on Lucas-Kanade tracking algorithm [11]. Evaluating script was written in Matlab environment. In the first image (prior the loading) an array of tracking features $(10 \times 15$ points $)$ was defined. As shown in Fig. 4 the displacement of each point was identified. Paths of each point were used to calculation local deformation in measured object.

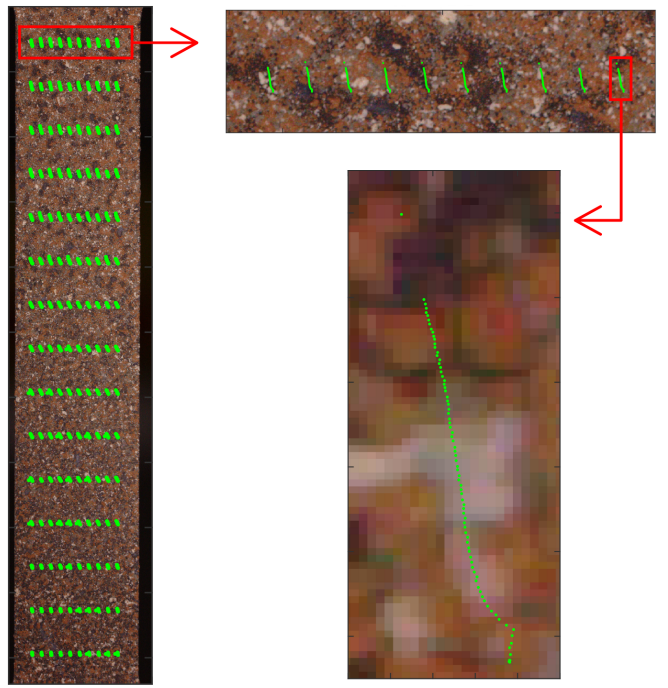

Figure 4. Detail of the displacement of a point during measurement.

Based on shifts of points the map of displacement was formed to verification DIC method. Obtained data were further processed to establish full-field strain maps.

\section{Results}

\subsection{Full-Field Strain MaP}

For representation inhomogeneities and local deformation in object full field maps were created. Calculation and evaluation those processes were completed using Matlab script as well. Displacements and strains calculated in each correlation point using set of Matlab scripts are represented by strain maps depicted in Fig. 5 to 9 From the results of the displacement mapping of the sample no. 22 (see Fig. 5) expected linear behaviour without significant local inhomogeneities was observed. Strains maps of selected samples of both types of pellets represented by sample no. 22 consisted of $13.0 \times 3.25 \mathrm{~mm}$ depicted in Fig. 8 and by sample no. 45 consisted of $25.0 \times 6.0 \mathrm{~mm}$ depicted in Fig. 9 discovered local strain concentrations (represented by red colour) indicating material imperfections. In case of $13.0 \times 3.25 \mathrm{~mm}$ pellets the absolute values are lower but spread on larger area compared to $25.0 \times 6.0 \mathrm{~mm}$ pellets specimen where deformation are higher in discontinuous area.

\subsection{Young's Modulus}

Calculation of Young's modulus was done by three different approaches. Firstly, results were computed from crossbeam displacement and force log. Another results were calculated using displacements of points acquired from DIC. Average displacement of first and last line of points was used to comparison with results calculated from $5^{\text {th }}$ and $11^{\text {th }}$ line of points. Similarly, results of two ways of calculation from DIC method were found. 


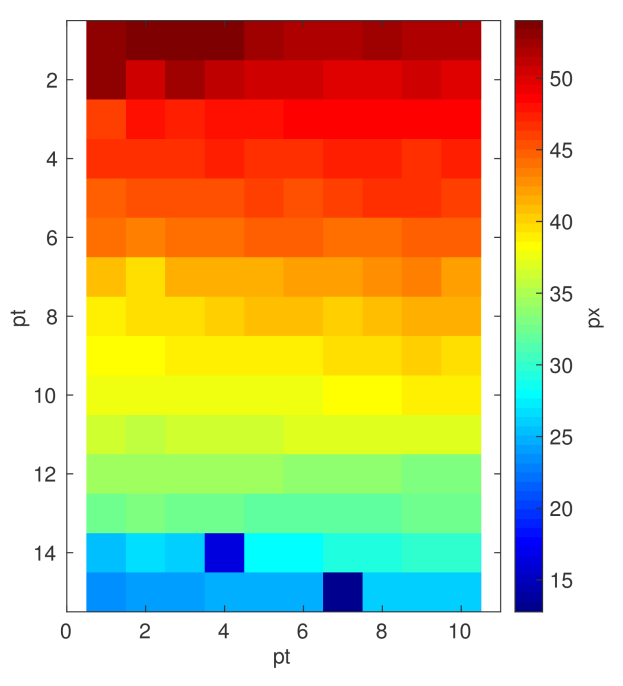

Figure 5. Map of the total displacements of points.

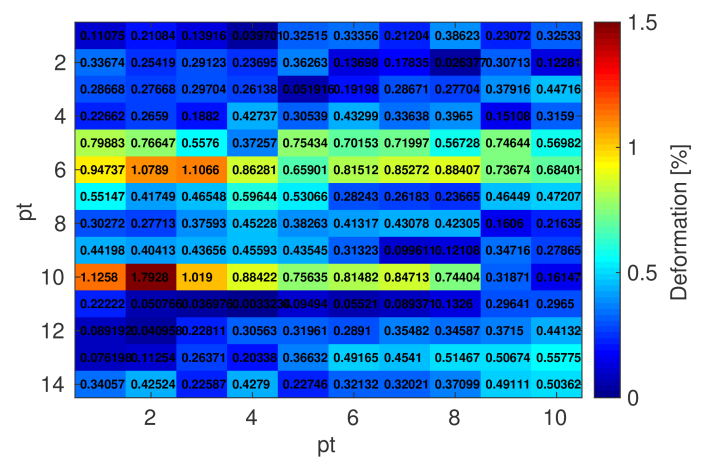

Figure 6. Full-field strain map of the sample 22 (smaller pellets).

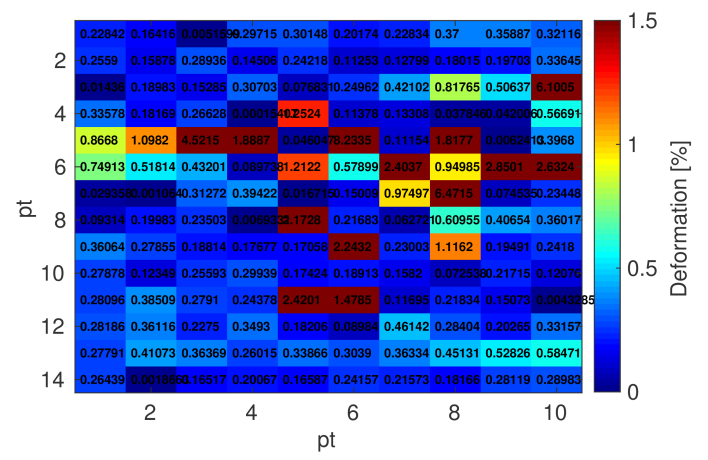

FiguRE 7. Full-field strain map of the sample 45 (bigger pellets).

- Green curve - optical strain measurement, calculated between first and last row of grid.

- Yellow curve - optical strain measurement, calculated between $5^{\text {th }}$ and $11^{\text {th }}$ row of grid.

- Red curve - calculated from crossbeam displacement.

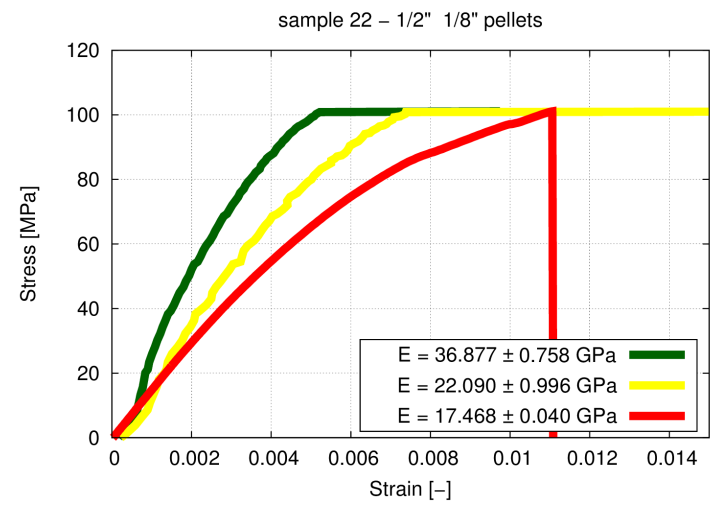

Figure 8. Stress-strain diagram of $13 \times 3.25 \mathrm{~mm}$ pellets; Sample 22.

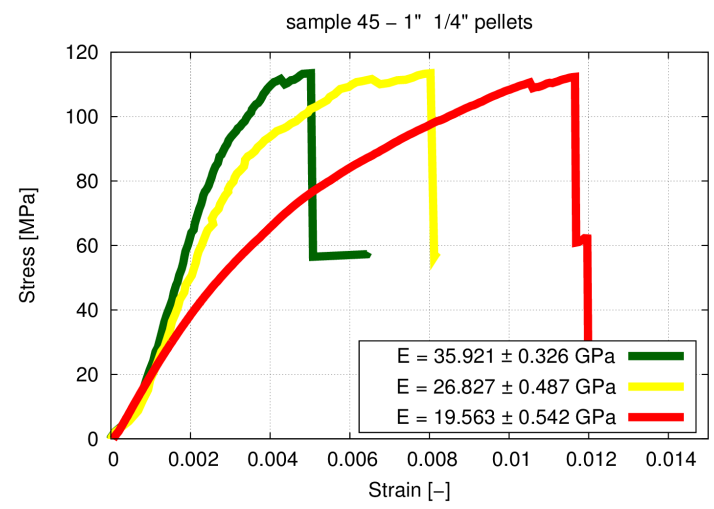

Figure 9. Stress-strain diagram of $25 \times 6 \mathrm{~mm}$ pellets; Sample 45.

\section{Conclusions}

Deformation behaviour of chopped fibre composites represented by stress-strain curves and strain maps was described based on optical measurement of standard tensile test. Similar elastic properties in comparison with long fibre samples [3] and small differences in Young's modulus values in each set were observed. In contrary significant differences in ultimate stress $(80-150 \mathrm{MPa})$ were observed. Differences caused by fabrication technology mainly given by imperfections in the material structure was measured. As expected, the values of strains was significantly lower using optical evaluation method. Strains derived from cross-head displacement were affected by backlash of the grips of the loading device. With respect to the measured data, the reliability of the optical method for investigation of local strain concentrations was proven. Delivered sets of tested material were considered still unsuitable for small structural parts for the mass production. The investigated composite material and requires further improvements of fabrication process.

\section{ACKNOWLEDGEMENTS}

The research was supported by Grant Agency of Czech Technical University in Prague (project no. SGS15/225/OHK2/3T/16), by Technology Agency from 
the Czech Republic (Grant no. TA03010209) and by institutional support RVO: 68378297.

\section{REFERENCES}

[1] D. Steenkamer, J. Sullivan. On the recyclability of a cyclic thermoplastic composite material. Composites Part B: Engineering 29(6):745-752, 1998.

[2] J. Gallagher, U. S. A. Force. USAF damage tolerant design handbook: guidelines for the analysis and design of damage tolerant aircraft structures : final report for period September 1980 to March 1984. No. v. 1 in USAF Damage Tolerant Design Handbook: Guidelines for the Analysis and Design of Damage Tolerant Aircraft Structures : Final Report for Period September 1980 to March 1984. Flight Dynamics Laboratory, Air Force Wright Aeronautical Labortories, 1984.

[3] J. Valach, D. Kytyr, T. Doktor, et al. Comparison of mechanical properties of CFRP laminate obtained from full-scale test and extrapolated from local measurement. Chemicke listy.

[4] D. Kytyr, T. Fila, J. Sleichrt, et al. Assessment of the post-impact damage propagation in a carbon-fibre composite under cyclic loading. Materials and Technology 48(5):25-28, 2014.
[5] P. Koudelka, T. Fila, T. Doktor, et al. Inspection of post impact fatigue damage in carbon fibre composite using modulus mapping technique. Key Engineering Materials 606(4):245-248, 2014.

[6] T. Doktor, J. Valach, D. Kytyr, et al. Analysis of cross-section surface roughness evolution of carbon fibre reinforced polymer under fatigue loading. Chemicke listy 106(3):399-400, 2012.

[7] Composites becoming the standard in aircraft seats. JEC Composite Magazine 43(23):34, 2006.

[8] R. Bockstedt, J. Sajna. Low cost composites based on long carbon fiber thermoplastics. Proceedings of SAMPE 2010 Conference, Anaheim, USA pp. 2011-2020, 1993.

[9] J. Dourmaxa, S. Bouvier, A. Aouafi, P. Vacher. Fullfield measurement technique and its application to the analysis of material behaviour under plane strain mode. Materials Science and Engineering A(500):47-62, 2009.

[10] I. Jandejsek, J. Valach, D. Vavrik. Optimalization and calibration of digital image correlation method. Proccedings EAN 2010 pp. 121-126, 2010.

[11] B. Lucas, T. Kanade. An iterative image registration technique with application to stereo vision. Proceedings of Image Understanding Workshop pp. 121-130, 1981. 